\title{
Estimation of source parameters of Chamoli Earthquake, India
}

\author{
Y PANDEY, R DhARMARAJU and P K S ChAUHAN \\ Central Building Research Institute, Roorkee 247667, India \\ e-mail: silcbri@nde.vsnl.net.in
}

The devastating earthquake $(\mathrm{mb}=6.6)$ at Chamoli, Garhwal Himalaya, which occurred in the morning hours on 29th March 1999, was recorded on Delhi Strong Motion Accelerograph (DSMA) Network operated by the Central Building Research Institute, Roorkee. In this paper the source parameters of this event calculated from the Strong Motion Data are presented. The seismic moment for this event has been found to be of the order of $10^{25}$ dyne.cm and the moment magnitude has been calculated in the range of $6.53-6.69$ at different stations. The stress drop and source radius for the earthquake are also calculated.

\section{Introduction}

The Himalayas, stretching from the PamirHindukush to the Arkans in Burma, is a classic product of a continent collision (Valdiya 1980, Seeber and Armbruster 1981, Ni and Barazangi 1984). The Himalayan seismic belt is known for its high seismicity for small to large magnitude earthquakes. This region has witnessed four large magnitude earthquakes (mag. >8.4) and nine earthquakes of magnitude $>7.0$ since 1897 . Besides these it has experienced two more devastating earthquakes of magnitude greater than 6.0 in the last decade namely the Uttarkashi earthquake in 1991 and the Chamoli earthquake in 1999 (Rajendran et al 2000, Rastogi 2000). The effect of these earthquakes was felt up to approx. $300 \mathrm{~km}$. in the city of Delhi. In the recent earthquake of Chamoli about hundred people have lost their lives, several hundred people were injured and about 50000 houses were damaged, apart from loss of property of worth crores of rupees. Aftershocks of this event were felt for several months.

When an earthquake takes place, certain amount of strain energy is released, resulting in a sudden drop of accumulated stress. Recent advances in the seismic source theory have improved our understanding of the body wave spectral characteristics and physical properties of the source such as seismic moment, stress drop and area of rupture. Brune (1970) has given a model to calculate source parameters using near and far field displacement amplitude spectrum as a function of the physical para- meters at the source. Abercombie and Leary (1993); Zobin and Hasakov (1995) and several others are notable recent contributors in the field of source parameter studies, in different parts of the world. Singh et al (1979) and Sharma and Wason (1994, 1995) have calculated source parameters for Himalayan and nearby regions. To the best of this authors' knowledge, the source parameter studies using strong motion data have not been carried out in India so far, though similar work has been undertaken in other parts of the world. One of such recent study is done by Olafsson et al (1998) on the Vatnafjoll earthquake in south Iceland. In the present study the source parameters for the 1999 Chamoli earthquake are calculated at three different sites using strong motion data recorded on Delhi Strong Motion Accelerograph (DSMA) network maintained by the CBRI.

\section{Data and methodology}

Sixteen Digital Triaxial Strong Motion Accelerographs (Altus K2) have been installed in and around Delhi under the DSMA network. All the 16 instruments are installed either at the basement or on the ground floor of buildings. The locations of SMAs, which are operating in this region at present, are shown in figure 1.

The Chamoli earthquake of 1999 was recorded on DSMA network at six stations, three located inside Delhi city and three outside the city. These stations

Keywords. Chamoli earthquake; strong motion accelerograph; seismic moment; source radius; stress drop; moment magnitude.

Proc. Indian Acad. Sci. (Earth Planet. Sci.), 110, No. 2, June 2001, pp. 171-177

(C) Printed in India. 


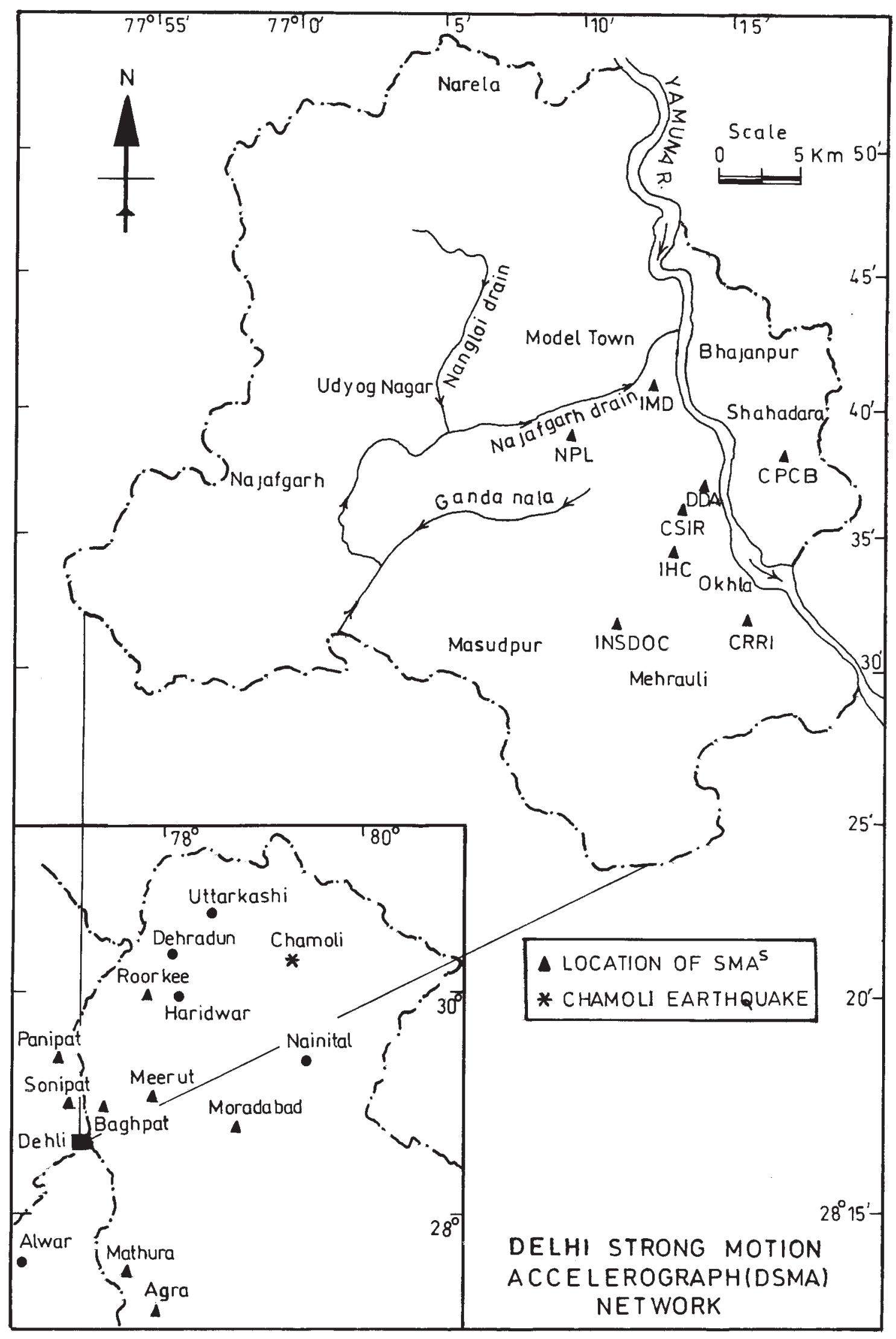

Figure 1. Locations of strong motion accelerographs network. 

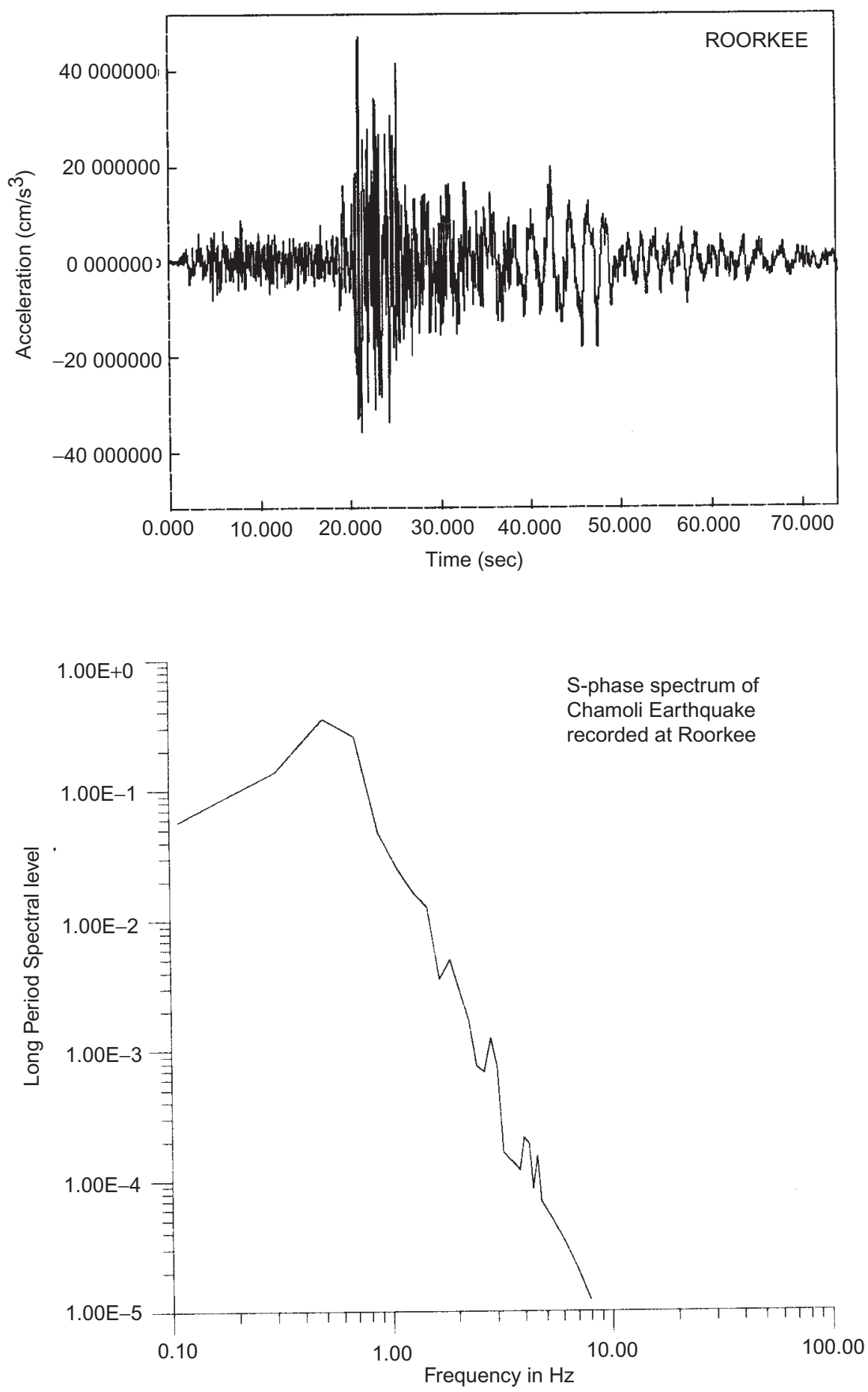

Figure 2 (a). Fourier spectra of the S-phase data at Roorkee station for the Chamoli earthquake.

are CPCB (East Arjun Nagar), CSIR (Rafi Marg) and IHC (Lodhi Road) in Delhi and Baghpat, Panipat and Roorkee. For source parameter studies the data from Roorkee, Panipat and Baghpat stations have been used as the body waves were distinctly recorded on these stations. Delhi being much more distant from the epicentre, could not record body waves.
The hypocentral parameters of the Chamoli earthquake as provided by the India Meteorological Department (IMD) are: Date: 29th March 1999; origin time: 00:35:13.4 (IST); epicentre: $30.41^{\circ} \mathrm{N} ; 79.42^{\circ} \mathrm{E}$; depth: $21 \mathrm{~km}$ and magnitude: $\mathrm{ML}$ 6.8 (IMD, 2000).

The source parameters were estimated by taking the fourier spectra of the pure S-phase displacement 

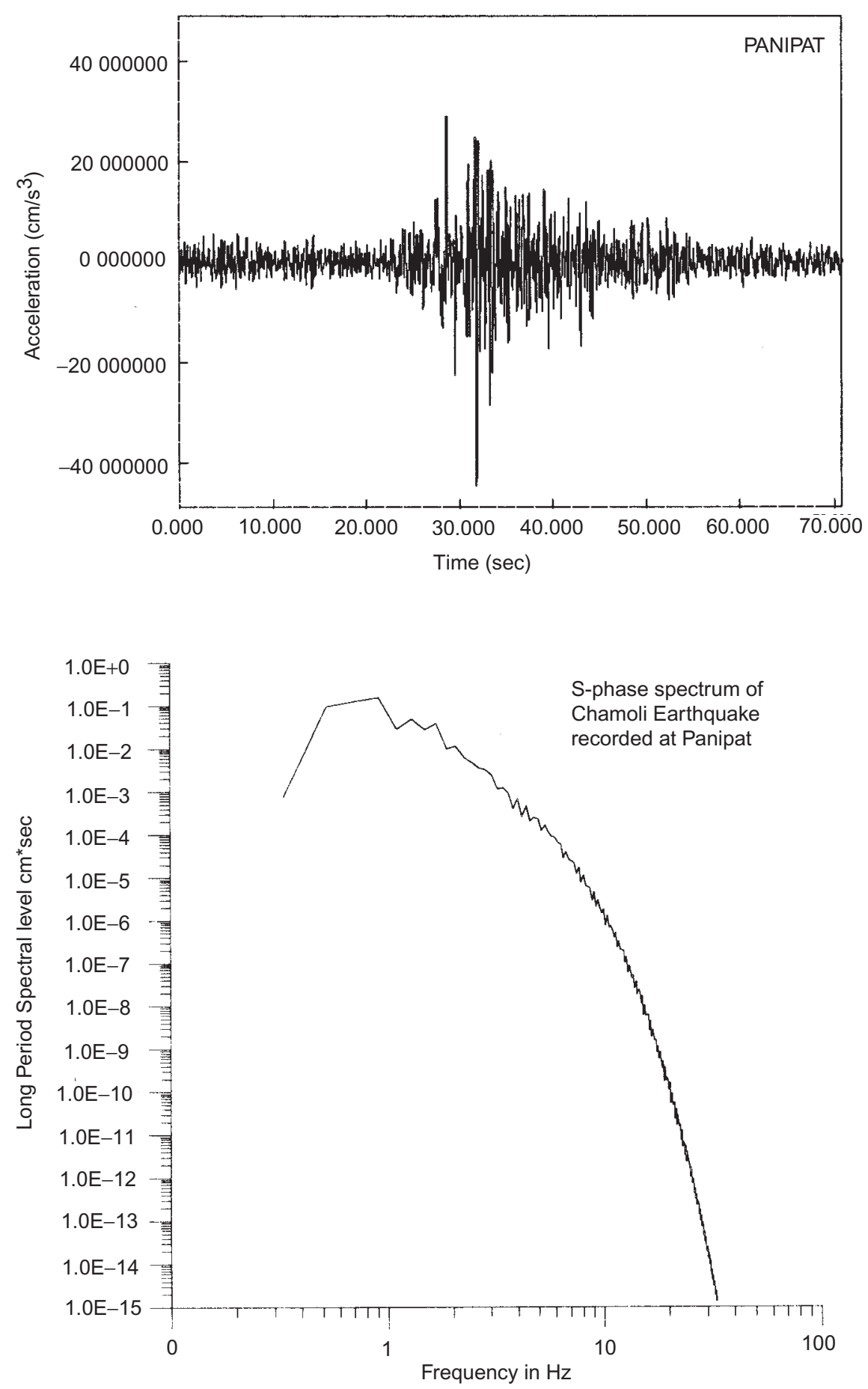

Figure 2 (b). Fourier spectra of the S-phase data at Panipat station for the Chamoli earthquake.

data (figure 2 a,b,c) using the standard fourier transformation programs. For this purpose the recorded acceleration data were integrated twice after applying the instrumental and baseline corrections. Before the marking of corner frequency and long period spectral level, the attenuation correction was applied assuming the well accepted 'Q' value of 300 for the Himalayan region as suggested by Sharma and Wason
(1994). The variables like long period spectral level $\left(\Omega_{o}\right)$, corner frequency $\left(f_{c}\right)$ were estimated and used to compute seismic moment $\left(M_{o}\right)$, circular source radius $(r)$ and stress drop $(\Delta \sigma)$ using following relations

$$
\begin{aligned}
M_{o} & =\left\{4 \Pi \rho R\left(V_{s}\right)^{3} \Omega_{o}\right\} / R_{\theta \Phi}, \\
r & =2.34 V_{s} / 2 \Pi f_{c},
\end{aligned}
$$



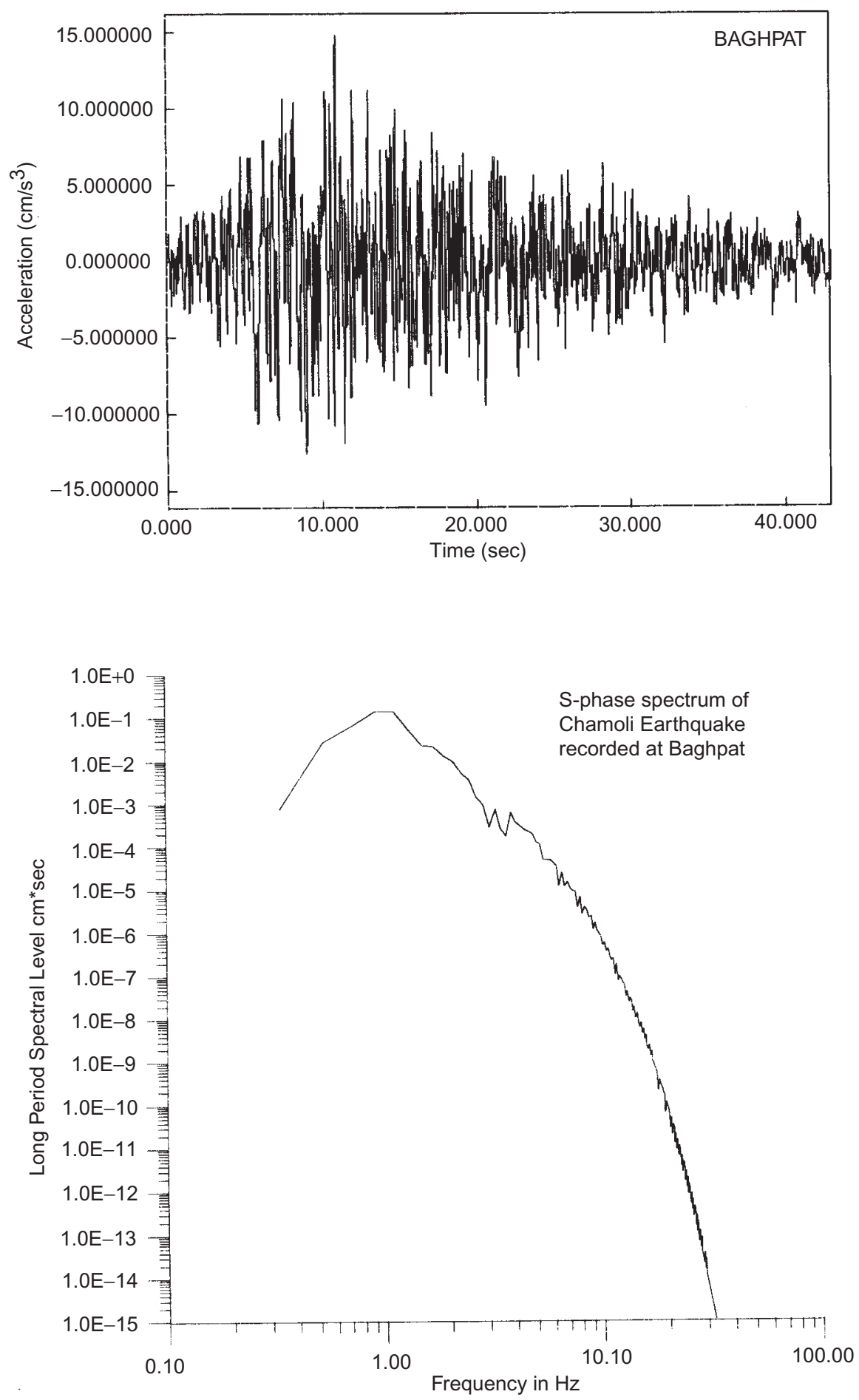

Figure 2 (c). Fourier spectra of the S-phase data at Baghpat station for the Chamoli earthquake.

where $M_{o}$ represents the seismic moment in dyne.cm which is the measure of size of an earthquake source and $R$ is the epicentral distance in $\mathrm{cm}$. $R_{\theta \Phi}$ has been calculated for this event and the values come out to be 0.14. $\rho$ is the density at the source in $\mathrm{gm} / \mathrm{cm}^{3}$ (Brune 1970). Quantities $r$ and $V_{s}$ denote the radius of the circular model in $\mathrm{km}$ and transverse wave velocity in $\mathrm{km} / \mathrm{sec}$ respectively. Values of $V_{s}$ and $\rho$ are taken to be $4.77 \mathrm{~km} / \mathrm{sec}$ (Wason et al 1999) and $2.7 \mathrm{gm} / \mathrm{cm}^{3}$ respectively in the present calculation of source parameters of 1999 Chamoli earthquake.

The stress drop in bars for the circular source model can be estimated with the help of the equation developed by Brune (1970);

$$
\Delta \sigma=7 M_{o} / 16 r^{3 *} 10^{-6}
$$


Table 1. Results of source parameter studies.

\begin{tabular}{lcccccc}
\hline Station & $\begin{array}{c}\text { Corner } \\
\text { frequency }\left(f_{c}\right)\end{array}$ & $\begin{array}{c}\text { Long period } \\
\text { spectral } \\
\text { level }\left(\Omega_{o}\right)\end{array}$ & $\begin{array}{c}M_{o} \text { in } \\
\text { dyne.cm }\end{array}$ & $\begin{array}{c}\text { Source } \\
\text { radius }(r) \\
\text { in km. }\end{array}$ & $\Delta \sigma$ in bars & $\begin{array}{c}\text { Moment } \\
\text { magnitude } \\
\left(M_{w}\right)\end{array}$ \\
\hline Roorkee & 0.6 & 0.3 & $12.40 \times 10^{25}$ & 2.96 & 2091 & 6.69 \\
Panipat & 0.8 & 0.1 & $6.94 \times 10^{25}$ & 2.22 & 2775 & 6.53 \\
Baghpat & 0.9 & 0.1 & $7.07 \times 10^{25}$ & 1.98 & 3984 & 6.53 \\
\hline
\end{tabular}

The moment magnitude $\left(M_{w}\right)$ can be estimated using the following formula:

$$
M_{w}=2 / 3 \log 10\left(M_{o}\right)-10.71
$$

where $M_{o}$ is seismic moment.

\section{Results and discussion}

The estimated seismic moment $\left(M_{o}\right)$ for the Chamoli earthquake using strong motion data comes out to be in the range $6.94 \times 10^{25}$ to $12.4 \times 10^{25}$ dyne.cm. The circular source radius $(r)$ using Brune's formula is in the range 1.98 to $2.96 \mathrm{~km}$. The stress drops for this event varies from 2091 to 3984 bars. The details of the results are shown in table 1 .

The peak ground accelerations recorded by DSMA network are shown in table 2. However, maximum peak ground acceleration of $352.83 \mathrm{~cm} / \mathrm{sec}^{*} \mathrm{sec}$ was recorded for this event at Gopeshwar, which is located nearest to the epicentre (IMD, 2000). The peak ground acceleration value gradually decreased up to $11 \mathrm{~cm} / \mathrm{sec}^{*} \mathrm{sec}$ at Delhi, which is about $300 \mathrm{~km}$ from the epicentre.

Table 2. Peak ground acceleration values.

\begin{tabular}{llc}
\hline Sl. No & \multicolumn{1}{c}{ Station } & $\begin{array}{c}\text { Peak } \\
\text { ground } \\
\text { acceleration } \\
\left(\mathrm{cm} / \mathrm{sec}^{*} \mathrm{sec}\right)\end{array}$ \\
\hline 1. & CSIR HQ, Rafi Marg & 10.65 \\
& New Delhi & \\
2. & CPCB, East Arjun & 15.00 \\
3. & Nagar New Delhi & \\
& IHC, Lodi Road & 11.47 \\
4. & New Delhi & 46.63 \\
5. & Roorkee & 14.72 \\
6. & Baghpat & 43.65 \\
\hline
\end{tabular}

For a better understanding of the Chamoli earthquake, accelerograms recorded on near source strong motion stations, in addition with DSMA data, were also studied and logical ground motion attenuation pattern was found when compared. The values of peak ground acceleration went on decreasing with distance - its value was $352.83 \mathrm{~cm} / \mathrm{sec}^{*} \mathrm{sec}$ at Gopeshwar, $46.63 \mathrm{~cm} / \mathrm{sec}^{*} \mathrm{sec}$ at a distance of $160 \mathrm{~km}$ in Roorkee and went down up to $11 \mathrm{~cm} / \mathrm{sec}^{*} \mathrm{sec}$ in Delhi.

\section{Acknowledgements}

Authors owe their thanks to the Director, CBRI for granting permission to publish this work. They express their sincere thanks to Prof. R N Iyengar (Ex-Director, CBRI and presently Professor at IISc Banglore), for his guidance and encouragement to pursue this work. Thanks are due to Shri S K Srivastava for the data from different locations and to Shri B S Bisht for his help in the preparation of the drawings. The help rendered by Prof. V N Singh and Dr. M L Sharma of the University of Roorkee is acknowledged with gratitude.

\section{References}

Abercombie R and Leary P 1993 Source parameters of small earthquakes recorded at $2.5 \mathrm{~km}$ depth, Cajon Pass, Southern California: Implications for earthquake scaling; Geophys. Res. Lett., 20, 1511-1514

Brune J 1970 Tectonic stress and seismic shear waves from earthquakes; J. Geophys. Res., 75, 4997-5009

IMD 2000 A report on the Chamoli Earthquake of March 29, 1999 and its aftershocks. Seismology No. 2/2000, p 70

$\mathrm{Ni} J$ and Barazangi M 1984 Seismotectonics of the Himalayan collision zone geometry of the underthrusting Indian plate beneath the Himalaya; J. Geophys. Res. 89(B2) 1147-1163

Olafsson S, Sigbjornsson R and Einarsson P 1998 Estimation of source parameters and $\mathrm{Q}$ from acceleration recorded in the Vatnafjoll earthquake in south Iceland; Bull. Seis. Soc. Am., 88(2), 556-563

Rajendran K, Rajendran C P, Jain S K, Murthy C V R and Arlekar J N 2000 The Chamoli Earthquake, Garhwal Himalaya: Field observations and implications for seismic Hazard; Current Science, 78, No. 1., p. 45-51

Rastogi B K 2000 Chamoli earthquake of magnitude 6.6 on 29 March 1999; Geol. Soc. India, 55, 505-514

Seeber L and Armbruster J G 1981 Great detachment earthquakes along the Himalayan arc and long term forecasting. In: Earthquake Prediction: An Int. Review, Am. Geophys. Union (Maurice Ewing Series), 4, 259-277

Sharma M L and Wason H R 1994 Occurrence of low stress drop earthquakes in the Garhwal Himalaya region; Phys. of Earth snd Planet Interior 85, 265-272 
Sharma M L and Wason H R 1995 Seismic momentmagnitude relationship for the Garhwal Himalaya region; Bull. Ind. Soc. Earth Tech. 351, 32(3), 85-95

Singh D D, Rastogi B K and Gupta H K 1979 Spectral analysis of body waves for earthquakes and their source parameters in the Himalaya and nearby regions; Phys. Of Earth and Planet. Interior. 18, 143-152

Valdiya K S 1980 Geology of Kumaun Lesser Himalaya, Wadia Institute of Himalayan Geology, Dehradun, p 291
Wason H R, Sharma M L, Khan P K, Kapoor K, Nandini D and Kara V 1999 Preliminary analysis of broadband seismic data of the Chamoli earthquake of March 29, 1999 and its aftershock sequence. In Proc. of the workshop on Chamoli Earthquake and its Impact WIHG, Dehradun, India.

Zobin V M and Hasakov J 1995 Source spectral properties of small earthquakes in the northern North Sea; Tectonophysics. 248, 207-218 